\title{
Structure and Properties of Titanium Doped Tungsten Disulfide Thin Films Produced via the Magnetron Co-Sputtering DC Technique
}

Jhonattan De La Roche ${ }^{1}$, Juan Manuel Gonzalez², Elisabeth Restrepo Parra ${ }^{3}$, Federico Sequeda ${ }^{2}$

\footnotetext{
${ }^{1}$ Laboratorio de Física del Plasma, Universidad Nacional de Colombia Sede Manizales, Manizales, Colombia. e-mail: jdey@unal.edu.co

${ }^{2}$ Laboratorio de Recubrimientos Duros y Aplicaciones Industriales - RDAI, Universidad del Valle, Cali, Colombia e-mail: jmgonzalezc@gmail.com, fsequeda@yahoo.com

${ }^{3}$ Universidad Nacional de Colombia Sede Manizales, PCM Computational Applications e-mail: erestrepopa@unal.edu.co
}

\begin{abstract}
In this work, titanium doped tungsten disulfide thin films $\left(\mathrm{WS}_{2}\right.$-Ti) were deposited on AISI 304 stainlesssteel substrates using the magnetron co-sputtering DC technique. Films were produced with varying titaniumcathode power from 0 to $25 \mathrm{~W}$. The titanium content of the $\mathrm{WS}_{2}$ structure was determined using energy dispersive spectroscopy (EDS), thereby obtaining a maximum of $10 \%$ for the sample grown at $25 \mathrm{~W}$. X-ray diffraction (XRD) results indicated, for the pure sample, the presence of a hexagonal phase of high intensity on the (103) plane. However, with the addition of titanium, the $\mathrm{WS}_{2}$ crystallinity was reduced; nevertheless, when the titanium content was equal to $10 \%$, nanocomposite formation was promoted. This effect was observed in TEM (transmission electron microscopy) images. Finally, the tribological behavior was determined using a ball on disk (BOD) test. With this method, friction coefficient curves were obtained with respect to the number of cycles, allowing the measurement of friction coefficient values of 0.1 for the pure sample and 0.15 for the sample grown at $5 \mathrm{~W}$. Because of the low thickness of the samples, all of them failed during the first cycles.
\end{abstract}

Keywords: Coatings, tungsten disulfide, titanium doping, wear, magnetron co-sputtering

\section{INTRODUCTION}

The use of solid lubricant has become a subject of growing interest in various industries, such as the aerospace, automotive and metal-mechanics industries [1-3], because of the ability to achieve coefficients of friction between 0.01 and 0.05 in controlled atmospheres. This type of material exhibits good performance under high-pressure and high-temperature conditions, in which a conventional lubricant may exhibit problems such as migration, evaporation and chemical instabilities [4]. Among the various solid lubricants, the transition-metal dichalcogenides (TMD) (sulfides, selenides or tellurides of tungsten, molybdenum and niobium) are intrinsic lubricants that have been studied over the past 50 years. Their excellent lubricant properties are based on their crystal anisotropy; moreover, under ultra-high-vacuum conditions, they can be considered to be frictionless materials, as they can exhibit coefficients of friction (COFs) lower than 0.01 [5].

In the case of $\mathrm{MoS}_{2}$ films, in vacuum and inert environments, the COF can reach values of 0.005 and 0.05 , respectively [6,7], with wear values on the order of $10^{-8} \mathrm{~mm}^{3} \mathrm{~N}^{-1} \mathrm{~m}^{-1}$ for several counter-pairs [6]. On the other hand, $\mathrm{WS}_{2}$ films exhibit great thermal stability, a working temperature higher than that exhibited by $\mathrm{MoS}_{2}$ (approximately $100{ }^{\circ} \mathrm{C}$ ) and COFs between 0.02 and 0.06 under controlled conditions [8,9]. Nevertheless, similar to the other TMDs, when $\mathrm{WS}_{2}$ is exposed to atmospheres that contain oxygen and water vapor, its intrinsic imperfections increase, rapidly deforming the crystalline structure; its lubricant properties 
and wear resistance then decrease dramatically [4]. To address this issue, researchers around the world have performed experiments focused on doping this material with various metallic ( $\mathrm{Ni}, \mathrm{Au}, \mathrm{Pb}, \mathrm{Ti}, \mathrm{Al})$

and non-metallic $\left(\mathrm{C}, \mathrm{PbO}, \mathrm{Sb}_{2} \mathrm{O}_{3}, \mathrm{ZnO}\right)$ elements [1,9] to obtain a stable structure and to avoid excessive wear caused by triboxidation.

In this paper, the effects of Ti doping on the structural, morphological and tribological properties of $\mathrm{WS}_{2}$ are studied. Films were producing using the magnetron co-sputtering technique. The Ti concentration was varied by changing the $\mathrm{Ti}$ cathode power. This study was performed to investigate the possible application of $\mathrm{WS}_{2}$ as a lubricant in wet environments.

\section{EXPERIMENTAL DETAILS}

$\mathrm{WS}_{2}$ and $\mathrm{WS}_{2}$-Ti thin films were deposited on AISI 304 stainless steel substrates using a commercial DC non-reactive magnetron co-sputtering system, the AJA ATC 1500. The substrates were polished until a specular surface was obtained; afterward, they were deeply cleaned with acetone in an ultrasonic cube for a duration of 15 minutes. Two targets of $\mathrm{WS}_{2}$ and Ti with purities of $99.95 \%$ and $99.99 \%$, respectively, were employed. A shutter was interposed between a target and a substrate for pre-cleaning the substrate and the target before beginning each experiment. The base vacuum pressure in the reactor was on the order of $1 \times 10^{-4}$ $\mathrm{Pa}$; then, plasma cleaning in the chamber under an argon atmosphere was applied to the samples for a duration of 15 minutes to remove any impurities that were not eliminated by the ultrasonic cleaning. The working pressure and target power densities were determined by obtaining the I-V plot for $0.4,0.5,0.7$, and $0.8 \mathrm{~Pa}$. Three samples were grown per each process conditions, obtaining a better repeatability when using a working pressure of $0.4 \mathrm{~Pa}$ [10-12]. WS $\mathrm{W}_{2}$ cathode was kept at a constant power density of $2.5 \mathrm{~W} / \mathrm{cm}^{2}$, while the power density of the Ti cathode was varied between 0 and $1.5 \mathrm{~W} / \mathrm{cm}^{2}$, taking values of $0,0.25,0.5,0.75$, 1 and $1.25 \mathrm{~W} / \mathrm{cm}^{2}$.

The structural characterization was performed using an X-ray diffractometer Bruker AXS D8 Advance model with Bragg-Brentano geometry and a $\mathrm{CuK} \alpha$ radiation source $(\lambda=1.5406 \AA)$, obtained a pattern was averaged from 5 measurements. The morphological and elemental composition analyses were carried out using a scanning electron spectroscopy-SEM Philips XL 30 TMP, applying the standard energy dispersive spectroscopy-EDS technique at $20 \mathrm{keV}$ and a magnification of 200x. Images at a scale of $2 \mathrm{~nm}$ were acquired using transmission electron microscopy-TEM equipment FEI Tecnai TF-20 FEG/TEM, 200kV by field emission (S/TEM) the probe used was Fischione PMT type high angle annular dark-field in STEM mode and the selected area diffraction patterns were acquired using the smallest size $200 \mathrm{~nm}$ diameter aperture. The thickness and roughness of the coatings were determined using a Veeco-Dektak 150 Profilometer, using a distance of 400 and $700 \mu \mathrm{m}$ for thickness and roughness respectively; furthermore, for ensuring the repeatability, 4 measures for each sample were performed. The tribological characterization was performed using a CSEM tribometer with a stainless steel ball AISI 440 of $6 \mathrm{~mm}$ in diameter, a load of $5 \mathrm{~N}$ and a linear velocity of $5 \mathrm{~cm} / \mathrm{sec}$, carrying out four repetitions for each test.

\section{RESULTS AND DISCUSSION}

\subsection{Energy Dispersive Spectroscopy (EDS)}

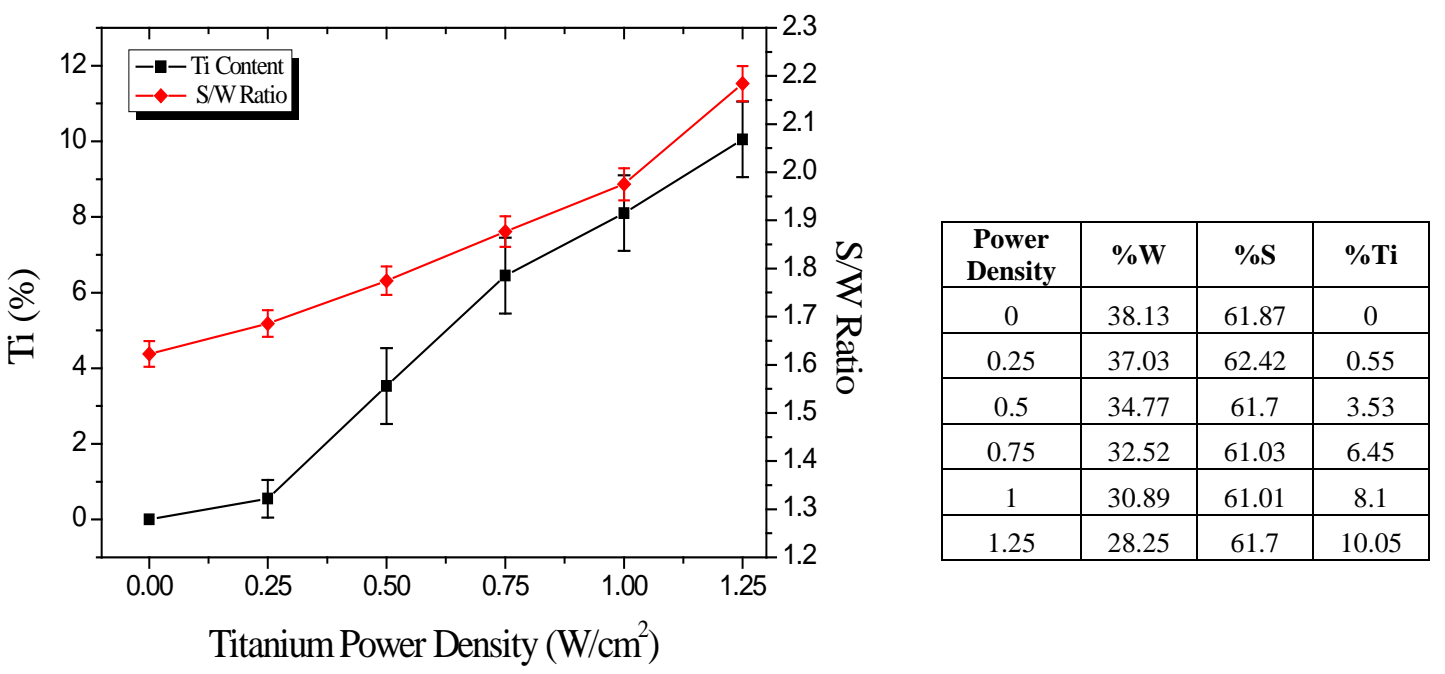

Figure 1: Titanium content of $\mathrm{WS}_{2}$ samples deposited at different titanium power density 
An elemental quantification of the $\mathrm{WS}_{2}$ and $\mathrm{WS}_{2}-\mathrm{Ti}(\mathrm{x})$ layers was performed, estimating the $\mathrm{Ti}$ percentage with respect to the Ti cathode power during the deposition process. Figure 1 shows the increment titanium content with increasing power density; this behavior is due to the greater amount of particles applied to plasma energy, increasing target pulverization, performing a deposition of more material on the substrate; for this reason, a maximum of $10 \%$ of titanium concentration for the sample grown at $1.25 \mathrm{~W} / \mathrm{cm}^{2}$ was obtained [13]. The sulfur/tungsten ratio (S/W) was also established in each measure. The pure sample shows a relationship of 1.62, which is common for coatings grown for this technique, because the sulfur and tungsten have different sputtering yield; therefore, the cathode will have a sulfur deficiency during the deposition. Moreover, part of the ejected sulfur atoms from the target are extracted by vacuum system, resulting in a reduction in the partial pressure of this element, which consequently makes films obtained with sulfur deficiency $[14,15]$. As titanium power density increases, an increment of the S/W ratio is evidenced; by a reduction of tungsten content in the sample, because presents a replacement of tungsten by titanium atoms, it can be occupy interstitial and substitutional sites on the lattice; however, following the rules of Hume-Rothery these materials have a partial solubility [15].

\subsection{Profilometry}

The roughness of the samples was measured with the Ra parameter (average roughness), where the average value for steel substrates, after polishing, was around $54.11 \mathrm{~nm}$. In figure 2, the average roughness vs. titanium power density behavior is observed; error bars were obtained averaging four measurements. After the film growth, titanium doping has no influence on roughness values of the films because no tendency is observed, and their distribution is wide for some values of titanium power density, this can be deduced by the spread of the data (dispersion bars); moreover, the equipment resolution for these measurements was $19 \mathrm{~nm}$, indicating that the dispersions are in its range, justifying this way the variation of the taken measures, which have closer values of the substrate roughness. Finally, the values obtained for $\mathrm{WS}_{2}$ and $\mathrm{WS}_{2}-\mathrm{Ti}$ films are acceptable, because they are at least 4 times below the film thickness, and these values are less than $90 \mathrm{~nm}$; above this amount, roughness influences values taken by nanoindentation technique [17].

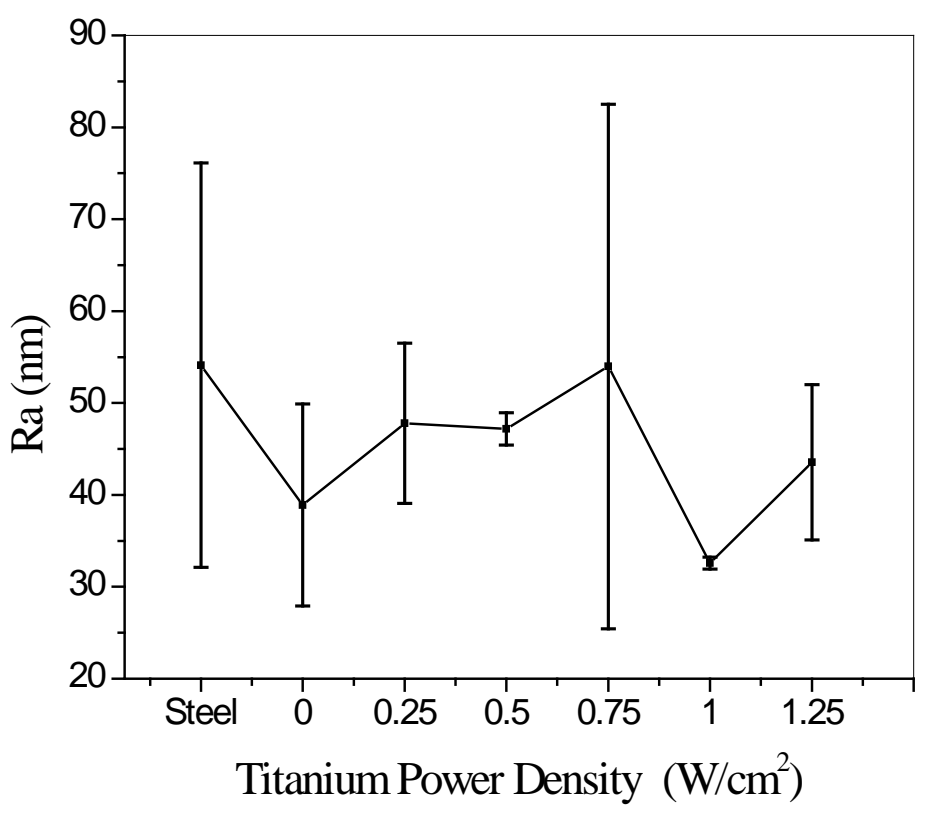

Figure 2: Average roughness (Ra) of $\mathrm{WS}_{2}$ samples deposited at different titanium power density

\subsection{X-ray diffraction (XRD)}

Figure 3 presents the diffraction patterns of the $\mathrm{WS}_{2}$ samples at various Ti cathode power densities. For the pure sample (without doping), peaks corresponding to a hexagonal structure (P63/mmc) with (102), (103), (110), (114), (108) and (203) planes are present at diffraction angles $2 \theta$ of $35.16^{\circ}, 39.61^{\circ}, 57.49^{\circ}, 66.22^{\circ}$, $69.02^{\circ}$ and $72.41^{\circ}$. 
The results indicate that the basal planes of the hexagonal cell were oriented perpendicular to the substrate surface (\|c or 1-type films) [18]. This preferential orientation occurs because during the deposition process, there are several active sites on the substrate; these sites react with the unsatisfied bonds at the lattice edges, forcing the basal planes to become aligned perpendicularly to the substrate because of the directionality of the dangling sulfur bonds [19]. Furthermore, a texture at the (006) plane was observed at a $2 \theta=43.45^{\circ}$, indicating that few basal planes were oriented parallel to the substrate surface ( $\perp$ c or 2 - type films) [18]. Finally, no peaks corresponding to the substrate were observed because the diffraction patterns were acquired at grazing angles.

The lattice parameters were calculated, yielding values of $a=3.178 \AA$ and $c=12.496 \AA$. Since the ratio $a / c=0.25$, the interplane basal distance is four times greater than the distance between nearest neighbors of the same plane; then, there is a Van der Waals type interaction, promoting low share stress; this characteristic is typical of laminar solids [20,21].

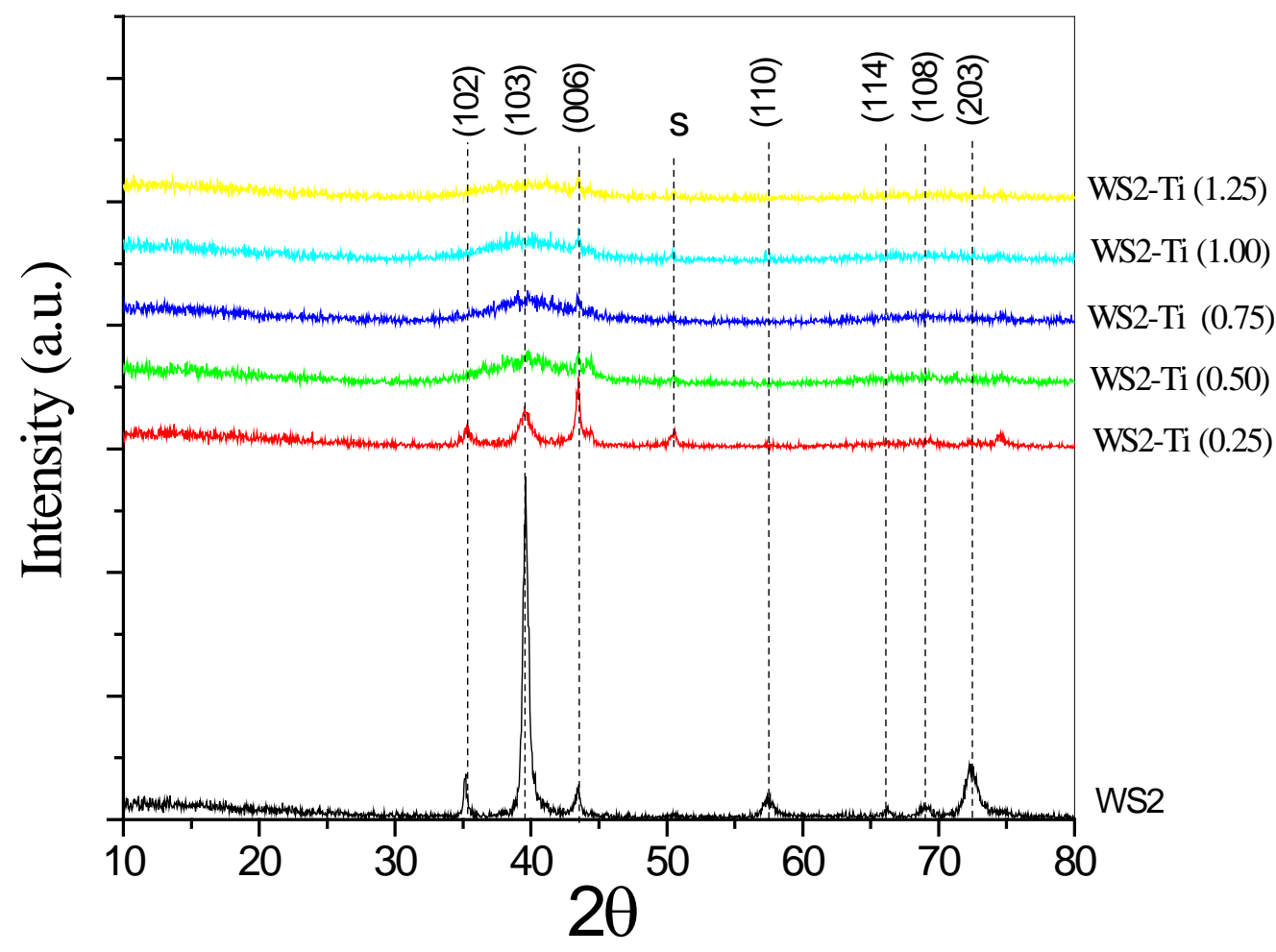

Figure 3: X-ray diffraction patterns of $\mathrm{WS}_{2}$ samples deposited at different titanium power density

When Ti was incorporated into the $\mathrm{WS}_{2}$ structure, the sample grown at $0.25 \mathrm{~W} / \mathrm{cm}^{2}(\sim 0.5 \% \mathrm{Ti})$ exhibited a decrease in intensity and loss of peaks, indicating a phase transition. In the pattern acquired from this sample, peaks corresponding to the substrate are evident, one of them overlapped with the (006) plane of the film. The presence of peaks associated with the substrate is attributed to film delamination. As the Ti percentage increased (with increasing power density of the Ti cathode), the peaks in the pattern disappeared, indicating changes in the microstructure of the film.

The crystallite size was calculated using the Scherrer equation for the samples without doping and the sample grown at $0.25 \mathrm{~W} / \mathrm{cm}^{2}$, yielding values of $39.13 \pm 2.33$ and $13.11 \pm 1.41 \mathrm{~nm}$, respectively. The decrease in the crystallite size of the sample grown at $0.25 \mathrm{~W} / \mathrm{cm}^{2}$ and the later separation of the peaks in the other patterns were caused by the $\mathrm{Ti}$ atoms preventing the nucleation and formation of the crystalline phase of $\mathrm{WS}_{2}$, thus producing an amorphous film [8]. This phenomenon also occurs in $\mathrm{MoS}_{2}$ films doped with Ti [22], SbOx [23], $\mathrm{Pb}$ [24] and $\mathrm{PbO}$ [25].

The microdeformation was calculated using the Stokes and Wilson method, for the pure sample yielding a value of $0.0076 \pm 0.0017$. This finding indicates that this sample possessed low strain because it was relieved by the movement of sliding planes [26]. For the sample grown at $0.25 \mathrm{~W} / \mathrm{cm}^{2}$, the value obtained was $0.02765 \pm 0.00206$; this increase relative to the pure sample indicates that the inclusion of $\mathrm{Ti}$ increased the strain, deforming the lattice. This process has been related to the position of Ti atoms between 
the planes of the $\mathrm{WS}_{2}$ structure, increasing lattice deformation. These defects become critical when Ti content increases until an amorphous structure is observed [8].

\subsection{Transmission electron microscopy (TEM)}
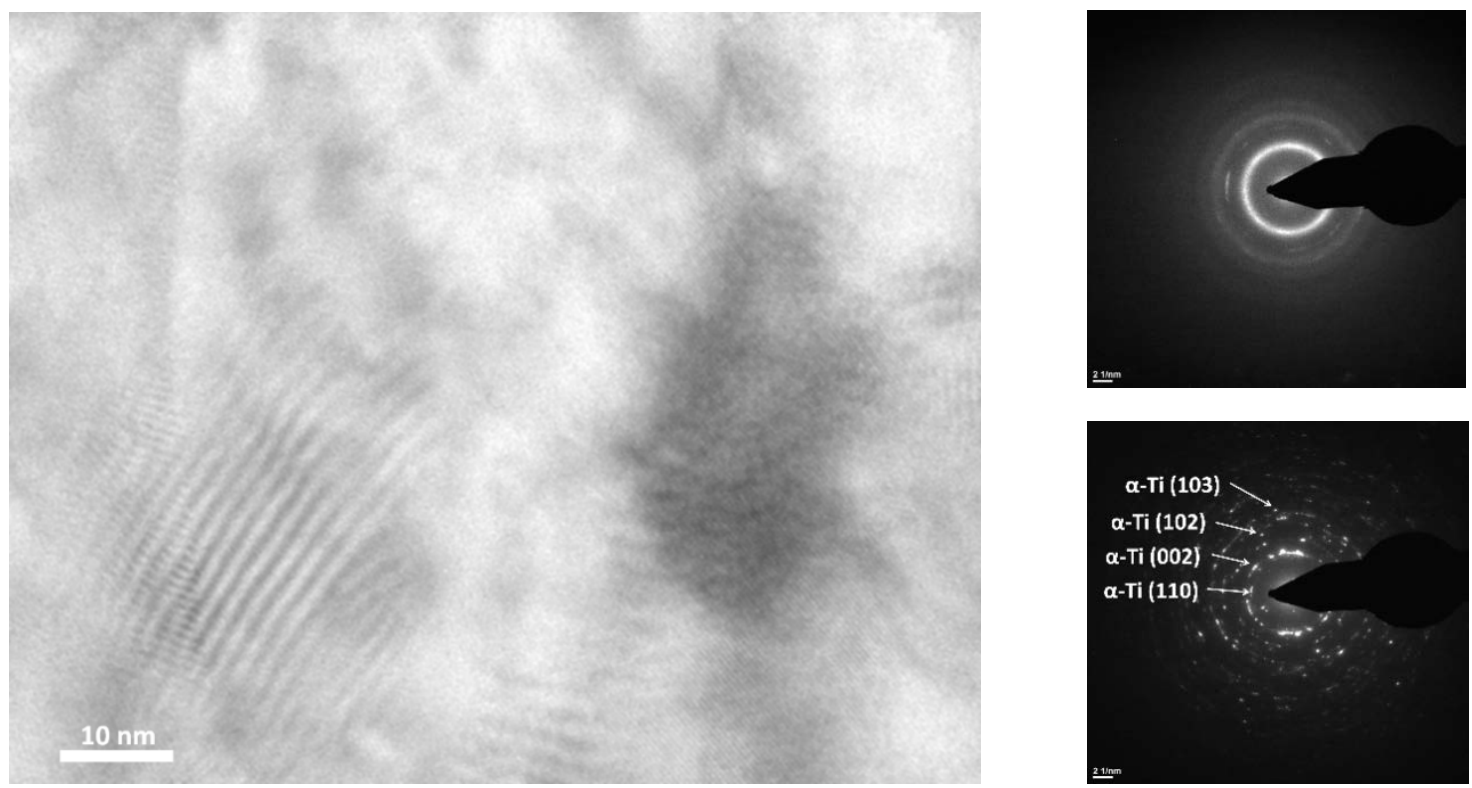

Figure 4: TEM image and selected area electron diffraction (SAED) of $\mathrm{WS}_{2}$ sample grown at $1.25 \mathrm{~W} / \mathrm{cm}^{2}$ titanium power density.

A TEM image of the sample $\mathrm{WS}_{2}-\mathrm{Ti}(1.25)$ is shown in figure 4. In this figure, phase separation is observed, as regions in which a precipitate of Ti nanocrystals with sizes between approximately 10 and 20 $\mathrm{nm}$ in an amorphous matrix of $\mathrm{WS}_{2}$ can be identified. This phenomenon is attributed to the supersaturation of $\mathrm{Ti}$, and it is known as spinodal decomposition [27,28]. T. W. Scharf et al. [8] have deposited $\mathrm{WS}_{2}$ films doped with Ti using the magnetron co-sputtering technique; in this work, a Ti concentration of approximately $7 \%$ was found, accompanied by the observation of a formation of Ti crystals in an amorphous matrix of $\mathrm{WS}_{2}$.

When the selected area electron diffraction technique (SAED) was performed in the crystalline regions, the hexagonal structure of $\mathrm{Ti}(\alpha-\mathrm{Ti})$ was identified with crystallographic directions in the $x y$ plane (cross section of the $x y$ plane, real zy plane); thus, the Ti was grown with the basal planes perpendicular to the substrate surface. A higher concentration of $\mathrm{Ti}$ in the sample $(\approx 10 \%)$ allowed the formation of the hexagonal phase with crystals of greater sizes; although tungsten stabilizes the $\beta$-Ti phase [29], it was insufficient in quantity to render this phase stable, thus allowing the formation of $\alpha$-Ti.

\subsection{Ball on disc (BOD)}

The variation in the coefficient of friction as a function of the number of cycles for the substrate, $\mathrm{WS}_{2}$ and $\mathrm{WS}_{2}-\mathrm{Ti}(\mathrm{x})$ using a steel ball (AISI 440) is shown in figure 5. It was observed that the $\mathrm{WS}_{2}$ layer exhibited the best behavior, demonstrating a coefficient of friction of 0.1 , because of its plasticity; nevertheless, at approximately 450 cycles, the film failed and began to exhibit a COF close to that of the steel, as the film was low in thickness and suffered from rapid wear. The sample grown at $0.25 \mathrm{~W} / \mathrm{cm}^{2}$ exhibited the best behavior among the doped films, demonstrating a COF that was slightly higher than that of the undoped film $(\approx 0.15$ ), which was maintained for approximately 100 cycles; in contrast, the other doped samples failed within the first cycles. The rapid damage of the doped coatings was caused by their increased fragility, which resulted from the incorporation of $\mathrm{Ti}$ atoms into the structure between the planes formed by sulfur [30]. This phenomenon limits the sliding of the planes, thereby reducing the plasticity of the film and thus the lubricant effect; nevertheless, reports have indicated that highly beneficial tribological properties of $\mathrm{WS}_{2}$ films can be achieved by doping them with $\mathrm{Ti}$ and/or other compounds [8, 22, 30-36]. In the case of the films studied in this work, their poor tribological properties can be attributed to the low coatings thickness (507.2 nm), which leads to rapid wear and prevents the films from being able to bear sufficient load. In such a case, the doping process does not improve the material's performance.

SEM images of the friction tests conducted using the steel ball are shown in figure 6. It can be observed that the predominant mechanism of wear was adhesion, as the low hardness and poor chemical stability (compared with $\mathrm{Al}_{2} \mathrm{O}_{3}$ ball) of the steel ball caused the ball to suffer wear, as corroborated by the 
EDS analysis. This process generated wear particles that were adhered to the track and other detached hard particles that generates plowing; moreover, the combined effect of plowing and adhesion produce delamination of the film. Plastic deformation, strain hardening and morphology of the wear particles generated during wear (belonging from both the coated surface and the ball) dominates the behavior of the wear mechanisms [11]. EDS spectra of the wear tracks for all films permit the identification of elements belonging to both the substrate ( $\mathrm{Fe}, \mathrm{Cr}, \mathrm{Mn}$ and $\mathrm{Ni}$ ) and the coating (W and $\mathrm{S}$ ). Regarding the ball wear, the ball was of similar composition to the substrate; thus, the elements that originated from it could not be differentiated from those of the substrate. The spectra also indicate the presence of $\mathrm{Ti}$ in the track, corroborating the role of this element in the material wear process.

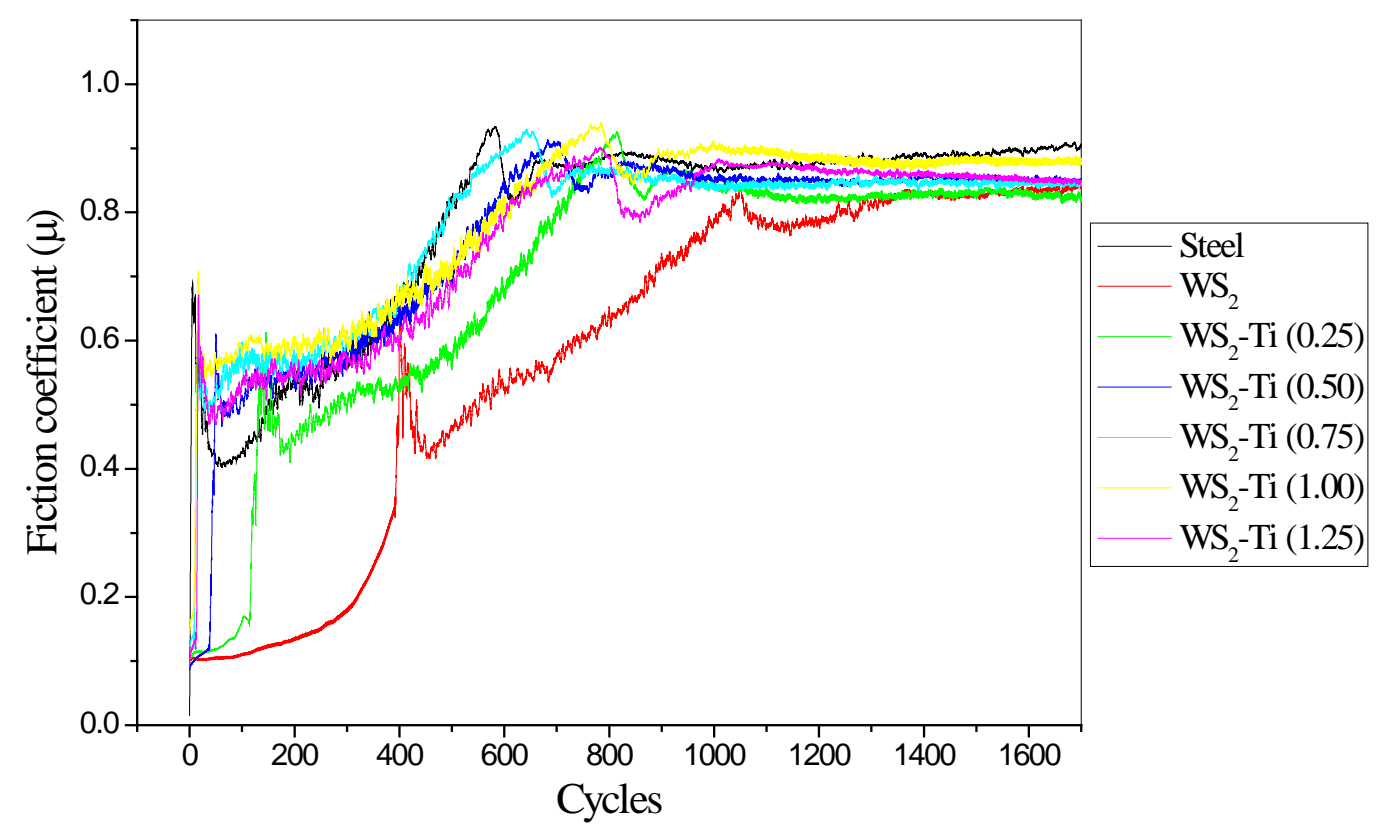

Figure 5: Friction coefficient- cycles curves of substrate, $\mathrm{WS}_{2}$ and $\mathrm{WS}_{2}-\mathrm{Ti}(\mathrm{x})$ with steel ball
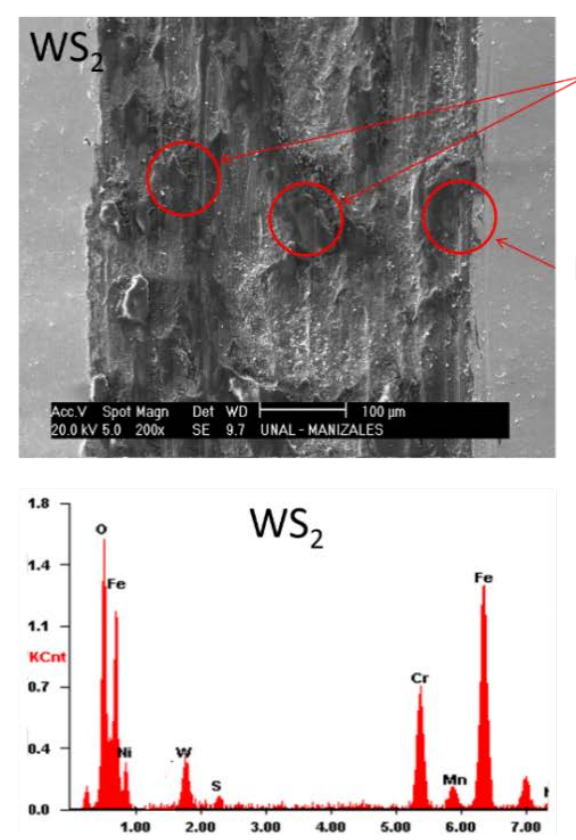
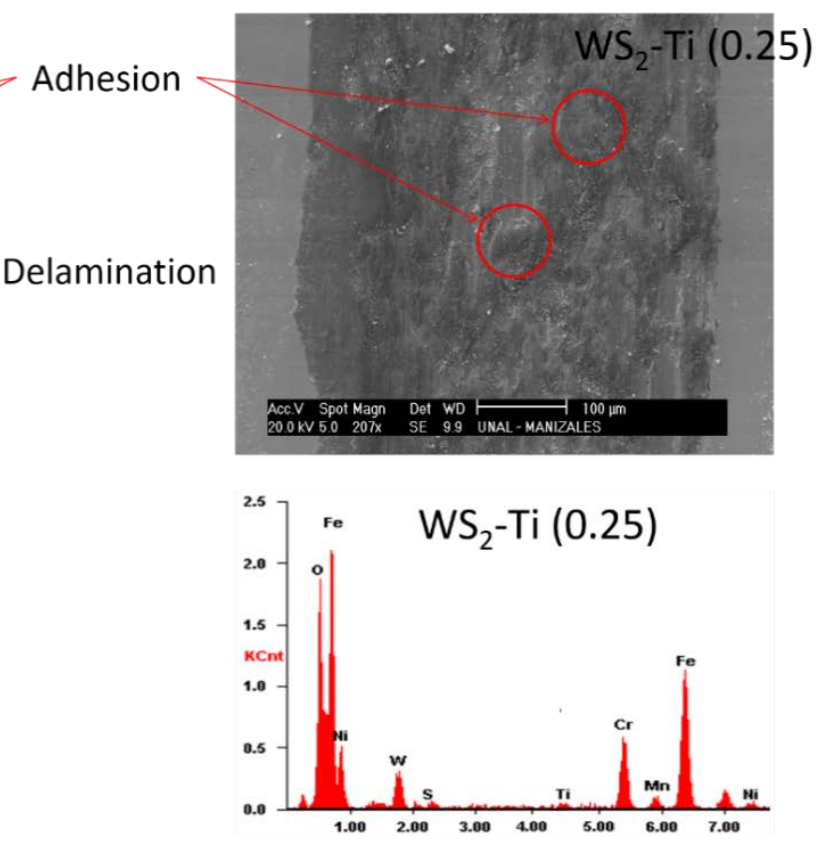

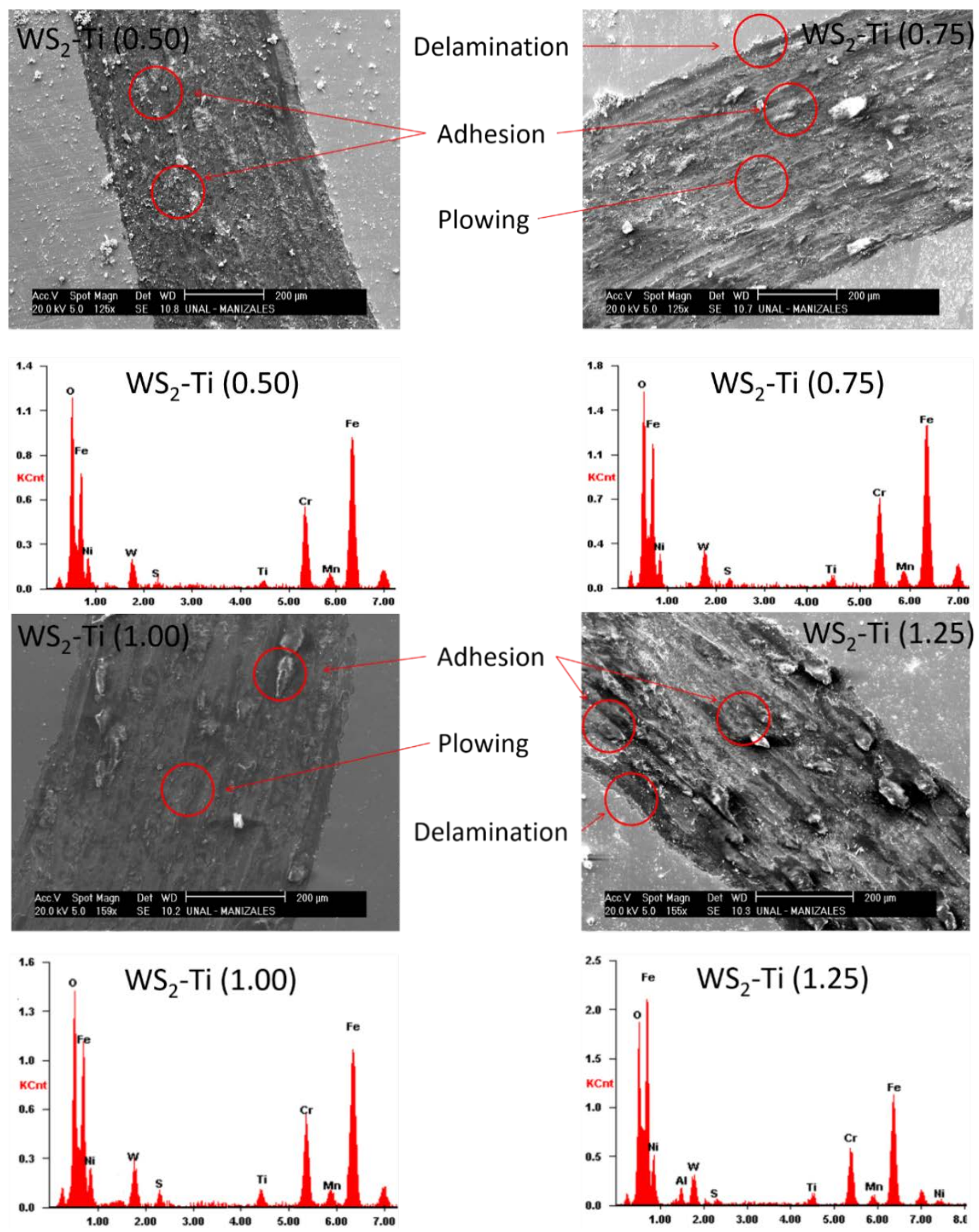

Figure 6: SEM images and EDS spectra of the wear track of the samples $\mathrm{WS}_{2}$ and $\mathrm{WS}_{2}-\mathrm{Ti}(\mathrm{x})$ after BOD test with steel ball

\section{CONCLUSIONS}

Titanium doped tungsten disulfide thin films $\left(\mathrm{WS}_{2}-\mathrm{Ti}\right)$ on AISI 304 stainless steel substrates were deposited using magnetron so-sputtering DC technique while varying the Ti cathode power.

The roughness of the coatings was determined via profilometry, and the results indicated that this parameter was not affected by the power of the Ti cathode. The approximate Ti percentage was obtained using the EDS technique, and the samples grown at $0.25 \mathrm{~W} / \mathrm{cm}^{2}$ and $1.25 \mathrm{~W} / \mathrm{cm}^{2}$ were found to exhibit the minimum and maximum values, respectively.

The XRD results demonstrated that the $\mathrm{WS}_{2}$ and $\mathrm{WS}_{2}$-Ti films exhibited a hexagonal structure with basal planes perpendicular to the substrate surface (1-type films) with a preferential orientation in the (103) plane.

TEM images at a scale of $5 \mathrm{~nm}$ and the SAED analysis conducted for the sample grown at $1.25 \mathrm{~W} / \mathrm{cm}^{2}$ of $\alpha$-Ti cathode power indicated the formation of nanocomposites that contained $\mathrm{Ti}$ crystals with sizes between 10 and $20 \mathrm{~nm}$ embedded in an amorphous $\mathrm{WS}_{2}$ matrix. 
The tribological analysis demonstrated that the doped films suffered damage because of their high fragility, which reduced their plasticity and lubricant behavior and was caused by the low thickness of the coatings. SEM images of the tracks produced by the steel ball showed that the predominant wear mechanism was adhesion.

\section{ACKNOWLEDGMENTS}

The authors gratefully acknowledge the financial support of Facultad de Ciencias Exactas y Naturales of the Universidad Nacional de Colombia sede Manizales and the Dirección Nacional de Investigaciones de la Universidad Nacional de Colombia sede Manizales DIMA during the course of this research under the project "Efecto del Dopaje de Titanio en Recubrimientos de Bisulfuro de Tungsteno $\left(\mathrm{WS}_{2}\right)$ Producidos por la Técnica de Magnetrón Co-Sputtering no Reactivo para aplicaciones en lubricantes sólidos”. Authors also want to acknowledge COLCIENCIAS for the support through "Convocatoria nacional para estudios a nivel de doctorado en Colombia 2009-Generacion del bicentenario”

\section{BIBLIOGRAPHY}

[1] MARTINEZ A. M., ECHEBERRIA J., "Towards a better understanding of the reaction between metal powders and the solid lubricant $\mathrm{Sb}_{2} \mathrm{~S}_{3}$ in a low-metallic brake pad at high temperature”, Wear, v. 348-349, pp. 27-42, 2016.

[2] REDDY PATURI U. M., REDDY MARURI R., REDDY NARALA S. K., "Measurement and Analysis of Surface Roughness in $\mathrm{WS}_{2}$ Solid Lubricant Assisted Minimum Quantity Lubrication (MQL) Turning of Inconel 718”, Procedia CIRP, v. 40, pp. 138-143, 2016.

[3] HILTON M. R., FLEISCHAUER P. D., “Applications of solid lubricant films in spacecraft”, Surface and Coatings Technology, v. 54/55, pp. 435-441, 1992.

[4] SINGH, H., MUTYALA, K.C., EVANS R.D., et al., "An investigation of material and tribological properties of $\mathrm{Sb}_{2} \mathrm{O}_{3} / \mathrm{Au}$-doped $\mathrm{MoS}_{2}$ solid lubricant films under sliding and rolling contact in different environments”, Surf. Coat. Technol., v. 284, pp. 281-289, 2015.

[5] POLCAR T., CAVALEIRO A., 2Review on self-lubricant transition metal dichalcogenide nanocomposite coatings alloyed with carbon2, Surf. Coat. Technol., v. 206, pp 686-695, 2011.

[6] JANG Y., YEO S., LEE H.-B.-R., KIM H., et al., "Wafer-scale, conformal and direct growth of $\mathrm{MoS}_{2}$ thin films by atomic layer deposition”, Appl. Surf. Sci., v. 365, pp. 160-165, 2016.

[7] DONNET, C, LE MOGNE, TH, MARTIN, JM., "Superlow friction of oxygen-free MoS2 coatings in ultrahigh vacuum2, Surf. Coat. Technol., v. 62, pp. 406-411, 1993.

[8] SCHARF, T.W., RAJENDRAN, A., BANERJEE, R., et al, "Growth, structure and friction behavior of titanium doped tungsten disulphide $\left(\mathrm{Ti}^{-} \mathrm{WS}_{2}\right)$ nanocomposite thin films”, Thin Solid Films, v. 517, pp. 56665675, 2009.

[9] XING Y., DENG J., ZHANG K., et al., "Fabrication and dry cutting performance of Si3N4/TiC ceramic tools reinforced with the PVD WS2/Zr soft-coatings”, Cer. Intern., v. 41, pp. 10261-10271, 2015.

[10] GONZALEZ, J.M., ORTEGA, C., AMAYA, C., et al., "Growing, Structure and Tribological Behavior of Titanium Doped Tungsten Disulphide/ Titanium Multilayers Thin Films (Ti-WS $/ 2 /)_{2}$ for Boundary Lubrication Protection” Society Of Vacuum coaters SVC - 57th Annual Technical Conference Proceedings, May 3-8, 2014, Chicago, IL USA., pp. 1-9, 2014.

[11] CANO, M. F., RESTREPO, J. S., RUDEN, A., et al., "The Effect of Substrate Temperatures on Tribological Behavior of Ti-Al-N Coating Deposited by Magnetron Sputtering”, Rev. En Society of Vacuum Coaters v.52 pp.. 37-43, 2009.

[12] RUDEN, A., RESTREPO-PARRA, E., PALADINES, A.U., et al., "Corrosion resistance of CrN thin films produced by dc magnetron sputtering”, Applied Surface Science v. 270, pp. 150-156, 2013.

[13] SESHAN K., "Handbook of Thin-Film Deposition Processes and Techniques - Principles, Methods, Equipment and Applications”, 2nd Edition, Noyes publications, pp 321- 326, 2002.

[14] GUANGYU D., DECHUN B., ZHEN T., et al., "Tribological behavior of RF sputtering WS $\mathrm{W}_{2}$ thin films with vacuum annealing”, Physics Procedia, v. 18, pp. 256-260, 2011.

[15] DU G.Y., BA D.C., TAN Z., et al., "Research on frictional behavior of tungsten disulfide thin films prepared by RF magnetron sputtering on restless steel”, Physics Procedia, v. 32, pp. 532 - 538, 2012.

[16] STIEHLER M., RAUCHHAUPT J., GIEGENGACK U., et al., "On modifications of the well-known Hume-Rothery rules: Amorphous alloys as model systems”, Journal of Non-Crystalline Solids, v.353, pp. 1886-1891, 2007. 
[17] WEIDNER M., BORRERO-LÓPEZ O., HOFFMAN M., et al., "Effect of substrate roughness on the contact damage of thin brittle films on brittle substrates”, Thin Solid Films, v. 518, pp. 5242-5248, 2010.

[18] GENUT, M., MARGULIS, L., TENNE, R., et al., "Effect of substrate on growth of WS2 thin films", Thin Solid Films, v. 219, pp. 30-36, 1992.

[19] BERTRAND P. A., “Orientation of rf-sputter-deposited MoS2 films”, J. Mater. Res., v. 4, pp. 180-184, 1989.

[20] STACHOWIAK G. W., BATCHELOR A. W., "Engineering trobology”, Third edition, elsevier , pp. 419-425, 2005.

[21] KARL-HEINZ, G. Z. “Microstructure and wear of materials”, Tribology Series, Elsevier, pp. 351, 1985.

[22] RENEVIER, N.M., V FOX.C., TEER, D.G., et al., "Coating characteristics and tribological properties of sputter-deposited MoS2 metal composite coatings deposited by closed field unbalanced magnetron sputter ion plating”, Surf. Coat. Technol., v. 127, pp. 24-37, 2000.

[23] HILTON M. R., JAYARAM G., MARKS L. D., "Microstructure of cosputter-deposited metal- and oxide-MoS2 solid lubricant thin films”, J. Mater. Res., v. 13, pp. 1022 - 1032, 1998.

[24] WAHL K.J., SEITZMAN L.E., BOLSTER R.N., et al., "Low-friction, high-endurance, ion-beamdeposited Pb-Mo-S coatings”, Surf. Coat. Technol., v. 73, pp. 152-159, 1995.

[25] ZABINSKI J.S., DONLEY M.S., DYHOUSE V.J., et al., "Chemical and tribological characterization of PbO-MoS2 films grown by pulsed laser deposition”, Thin Solid Films, v. 214, pp. 156-163, 1992.

[26] VOEVODIN A.A., FITZ T.A., HU J.J., et al., "Nanocomposite tribological coatings with -chameleon\| friction surface adaptation”, J. Vac. Sci. Technol. A, v. 20, pp. 1434-1444, 2002.

[27] FAVVAS E. P., MITROPOULOS A. CH., "What is spinodal decomposition?”, J. Eng. Sci. Technol. Review, v. 1, pp. 25- 27, 2008.

[28] PETROV, I., BARNA, P. B., HULTMAN, L., et al., "Microstructural evolution during film growth", J. Vacuum Sci. Technol., v. 21, pp. 117-128, 2003.

[29] WEISS, I., SEMIATIN, S.L., "Thermomechanical processing of beta titanium alloys—an overview", Mater. Sci. Eng. A, v.243, pp. 46-65, 1998.

[30] TEER, D.G., "New solid lubricant coatings”, Wear, v. 251, pp. 1068-1074, 2001.

[31] SUNDERBERG, J., NYBERG, H., SÄRHAMMAR, E., et al., "Influence of composition, structure and testing atmosphere on the tribological performance of W-S-N coatings", Surf. Coat. Technol., v. 258, 86-94, 2014.

[32] DEEPTHI, B., BARSHILIA, H. C., RAJAM, K.S., et al., "Structure, morphology and chemical composition of sputter deposited nanostructured Cr-WS2 solid lubricant coatings", Surf. Coat. Technol., v. 205, pp. 565-574, 2010.

[33] GUSTAVSSON, F., JACOBSON, S., CAVALEIRO, A.,” Ultra-low friction W-S-N solid lubricant coating”, Surf. Coat. Technol., v. 232, pp. 541-548, 2013.

[34] XU, S, GAO, X., HU, M.,et al., "Morphology evolution of Ag alloyed $\mathrm{WS}_{2}$ films and the significantly enhanced mechanical and tribological properties”, Surf. Coat. Technol., v. 238, pp. 197-206, 2014.

[35] POLCAR, T., CAVALEIRO, A., "Review on self-lubricant transition metal dichalcogenide nanocomposite coatings alloyed with carbon”, Surf. Coat. Technol., v. 206, pp. 686-695, 2011.

[36] AHN, S.H., LEE, J.H., KIM, J.G., et al., "Localized corrosion mechanisms of the multilayered coatings related to growth defects”, Surf. Coat. Technol., v. 177 -178, pp. 638-644, 2011. 